\title{
ORGANIZATION OF APPLIED RESEARCH
}

$\mathrm{E}$

IGHT annual conferences on the administration of research have been held in recent years in the United States. The interest in research administration is growing with its importance, and technical assistance missions sponsored by the Organization for European Economic Co-operation visited research establishments in Western Europe in 1951, and the United States and Canada in 1952. Their observations and conclusions have been published in three volumes under the general title "The Organization of Applied Research in Europe, the United States and Canada" (see Nature, 174, 778; 1954).

In spite of its manifest importance-it is reported that the United States alone is now spending three billion dollars annually on research-no conference on research organization had been held at an international level until that which took place in Nancy during October 11-15, 1954, arranged by the European Productivity Agency. Moreover, it is perhaps significant, and possibly strange to British ideas, that according to one delegate such a conference could not have been convened five years earlier. The conference was distinctly European, with about one hundred delegates from Western Europe and with American representatives as observers. As such, the many and varied expressions of opinion referred largely to the problems and difficulties of Western Europe.

Three separate approaches to the central theme were made on each of three succeeding days. The first day was devoted to the subject of "The Practical Organization of Research"; the second to "The Human Factor in Research and Team Work" ; and the third to "The Dissemination of Results of Research and their Implementation". Each day's papers and discussion were summarized by a series of 'conclusions' which, it is hoped, will provide springboards for action in the different countries represented.

Papers at the first session were delivered by $\mathrm{Dr}$. L. Henry (Belgium), Dr. D. W. Hill (Great Britain) and Prof. M. Letort (France). To some extent the discussion inevitably tended to centre around the relations between universities and industry-a major problem which has not yet been solved in Europe. It was generally considered that, while universities and industry must be brought closer together, each recognizing and, indeed, catering for the needs of the other, the American solution of extensive applied research projects in universities has progressed too far in one direction, to the possible detriment of the pure research function of the university. This led naturally to a discussion of how much applied research a university can undertake, in order to assist industry and strengthen its teaching function without undermining its research function.

Attempts to define the problem resulted, despite a plea from the chairman, Dr. A. King (Great Britain), in a discussion of the meanings of pure and applied. research. In this connexion a phrase used by Prof. Maurice Letort (France) sticks in the memory: in pleading for a recognition that applied research could often be sufficiently fundamental to satisfy the strictest purists, he described the kind of applied research which could usefully be done in universities, and which is already the main occupation of central reseßrch organizations, as "directed basic research"
- that is, fundamental research directed to a useful end. It was Prof. Letort, too, who probably gave the last word on this subject. Expressing his conviction that the dichotomy of pure and applied research is, in fact, non-existent, he pointed out that, since there must be some choice of subject, the academic research worker should choose a field with a big hinterland rather than one which would yield immodiate technical results.

The conclusions of the session reflected the discussion, especially with their insistence upon the need for applied research, the interdependence of academic research and industrial development, the need to preserve the freedom of academic research, and the desirability of governments assisting research of all kinds both directly and by fiscal policies which encourage research expenditure.

The discussion on the second day was remarkable in that human factors had never before been discussed at a conference in Europe, and no less so in that the British delegates listened intently but made only one very brief contribution to it. It was evident that the human problems of Continental Europe are not those either of Great Britain or the United States. The chairman, Mr. V. Lasareff (Organization for European Economic Co-operation), emphasized what is perhaps not generally recognized, namely, that, in applied research, productivity depends more upon the human factor than upon any other. The importance of the human factor can therefore scarcely be over-estimated. There can be little question that, of all the problems of research, the human ones, particularly the reconciliation of the interests of the community with those of the individual, present the widest differences between countries. For this reason, the last conclusion of the day, though apparently the most innocuous, may in the long run prove to be the most effective. This conclusion adopted a suggestion from Mr. Lasareff that the participating countries should compare their methods for selecting and evaluating staff. This should prove a relatively simple, but possibly very rewarding, task for the Organization for European Economic Co-operation.

After recognizing the importance of human problems in research, other conclusions directed attention to the need to provide both prestige and material satisfaction for the research worker, to the need for security, to the recognition of the value of research training for high industrial positions, and to the desirability of selecting research directors as much for their aptitude for leadership as for their scientific knowledge. More controversial, perhaps, was a conclusion that education from school-days onwards should aim at emphasizing the importance of research and preparing young people for teamwork and its discipline.

An absorbingly interesting paper on the evening of the second day, by Dr. J. W. Barker (United States), outlined the conception, philosophy and practice of the Research Corporation of New York, and introduced the subject of the patenting of research results. This was followed on the third day by an exposition of his views by Signor L. Morandi, vice-president of the Montecatini Company of Italy. The subsequent discussion on patents, though interesting, could scarcely be said to add much to the vast experience 
gained by the Research Corporation of New York and so fully put at the disposal of the conference by Dr. Barker.

The remainder of the discussion on the third day was largely concerned with the dissemination of research results. Documentation methods were reviewed in detail, and it was concluded that if efficiently pursued they will largely meet the needs of science and technology, but that the conventional methods do not fit the demands of the smaller firms. A recommendation was therefore adopted that the European Productivity Agency should encourage study designed to solve this aspect of the problem. On a wider approach, it was concluded that the knowledge of the impact of research on a dynamic civilization should be diffused as widely as possible. As Dr. J. S. Whitehead (Great Britain) pointed out in his paper, it is desirable to establish a climate of public opinion favourable to science, in order to ensure its widest application in national life. Such a climate, when established, affects influential people - those who have the direction of affairs-so that they take decisions in line with the needs of science.

To the present writer, at least, it was a matter of regret that more was not said on the implementation of the results of research, for this is a crucial point to which a whole conference might well be devoted. We are commonly told that only a small proportion of research results are capitalized, and that many research organizations could now be well employed ensuring the application of past results for the benefit of industry, rather than piling up new ones to be cast into the limbo with the old. It would be interesting to discuss whether this is true or not, and if so, why. Are there multitudinous results potentially valuable to industry, available and unused? If so, is it the fault of industry or research ? Is it the cost of development or the fear of obsolescence? Or is it fiscal policies or innate conservatism, either on the part of industry or of its customersthe public ? It is gratifying to know that the Applied Research Division of the European Productivity Agency is now planning a preliminary survey on the development of inventions. Its report, when available, might well form the basis of a future conference.

As was pointed out during the conference, research has been revolutionized during the past twenty-five years. No greater evidence of this could be forthcoming than the holding of such a meeting. Nevertheless, it is to be hoped that none of the delegates believes the conference to have been an end in itself. It was an opportunity for sharpening wits, comparing notes, receiving new points of view-all with the object of returning to the various countries represented to try them out in practice. For, when all is said and done, research organization is not yet a science but an art, and an empirical art at that, so that despite the conclusions no one is likely to dispute the wise words of Prof. M. Letort, "No authoritarian measure or administrative rule can create that confidence and goodwill which are the essential conditions of fruitful collaboration", which is the basis of successful research. With this background, the delegates naturally accepted a final conclusion that a similar conference dealing with the aspects of co-operation in research should be held in a year or two's time.

It would be ungracious to conclude this report without a reference to the excellent arrangements made for the conference by the European Productivity Agency and the University of Nancy. The success of the occasion was due in no small measure to the meticulous organization; and the gratitude of the participants will be directed especially to the rector of the University, Dr. J. Capelle, who also acted as secretary of the conference and who was unsparing in his efforts on their behalf.

D. W. HrLL

\section{AERATION IN INDUSTRIAL FERMENTATIONS}

$\mathrm{O}^{\mathrm{N}}$ January 12 the Society for Applied Bacteriology and the Microbiology Group of the Society of Chemical Industry held a joint meeting to discuss "Aeration in Industrial Fermentations". Dr. L. A. Allen was in the chair. Both the microbiological and the physical aspects of the subjects were considered, four papers being given and a short film shown.

In the opening paper, by A. L. Downing and G. A. Truesdale, Mr. Downing described some factors affecting the rate of solution of oxygen in water. The data were obtained from laboratory experiments designed to provide information about re-aeration in a polluted estuary. Relatively small changes in rate of solution of oxygen, expressed as an exit coefficient, resulted from the action of mixing currents or of air-streams forced tangentially over the surface, provided that the surface remained largely undisturbed. Increasing the rate of mixing beyond the point at which vortices were formed caused a rapid increase in exit coefficient, high rates of solution being ultimately attained. Similarly, the exit coefficient increased rapidly as the surface was increasingly disturbed by air-streams having velocities exceeding a critical value equivalent to $6-7 \mathrm{~m}$./ $/ \mathrm{sec}$. at $10 \mathrm{~m}$. above the surface. Increasing the height or frequency of waves, generated mechanically, caused an approximately linear increase in exit coefficient. Under different conditions of surface agitation the exit coefficient increased linearly with increasing temperature in the range $0-35^{\circ} \mathrm{C}$. The mean value of the temperature coefficients of the exit coefficient (defined as the increase in exit coefficient expressed as a percentage of the value at $20^{\circ} \mathrm{C}$. per deg. C. increase in temperature) was $2 \cdot 37$. Films of oil on the surface caused little effect until their thickness exceeded $10^{-4} \mathrm{~cm}$. Except when fracture of the film occurred, the exit coefficient was steadily reduced as the thickness was inereased from $10^{-4} \mathrm{~cm}$. to $10^{-1} \mathrm{~cm}$. Soluble surface-active agents, on the other hand, caused reductions in rate of solution which increased with increasing concentrations up to 1.0 p.p.m. but which tended to a limiting value.

The mechanics of bubble formation was then discussed by Mr. R. H. Bowers, who prefaced a description of his experimental work with a review of data obtained by other investigators. Datta and his co-workers showed that the measured size of bubbles issuing from a single open-ended tube, at low rates of flow of gas, agreed approximately with a theoretical formula derived by equating surface tension and buoyancy forces. As the rate of flow of gas was increased, the bubbles became larger. Van Krevelen has suggested a mechanism from which expressions for the size of both very large and small bubbles can be derived. In many industrial fermentations high flows of gas are required, and, if a simple perforated sparger is used, large bubbles are formed, which can lead to poor aeration. Bubbles produced from porous 